\title{
Increment of Heterogeneous Knowledge in Enterprise Innovation Ecosystem: An Agent-Based Simulation Framework
}

\author{
Rong Wu $\mathbb{D}^{1},{ }^{1}$ Zhiqiang Wang $\mathbb{D}^{2}{ }^{2}$ and Qinfen Shi $\mathbb{C}^{3}$ \\ ${ }^{1}$ Management Science Institute, Hohai University, Nanjing 210098, China \\ ${ }^{2}$ Business School, Hohai University, Nanjing 210098, China \\ ${ }^{3}$ Business School, Suzhou University of Science and Technology, Suzhou 215009, China \\ Correspondence should be addressed to Qinfen Shi; shiqf@njupt.edu.cn
}

Received 19 May 2021; Accepted 6 July 2021; Published 20 July 2021

Academic Editor: Yi Su

Copyright (C) 2021 Rong Wu et al. This is an open access article distributed under the Creative Commons Attribution License, which permits unrestricted use, distribution, and reproduction in any medium, provided the original work is properly cited.

How can enterprises acquire knowledge resources quickly to maintain a competitive advantage in the market has become the focus of attention among academic circles and enterprises in the era of the knowledge economy. Based on the ecology theory, this paper analyzed the characteristics of the innovation subject and the rules of the heterogeneous knowledge interaction between innovation subjects. Then, this paper proposed a multiagent-based model of EIE (enterprise innovation ecosystem) heterogeneous knowledge increment to simulate the interactions between innovation subjects. By combining the biotic factors (government and service institutions) and abiotic factors (economical, social, and cultural), this paper designs eight different innovation environment scenarios to explore the dynamic impacts of these factors on EIE heterogeneous knowledge increment. The research findings were as follows: (1) In the introduction stage of innovation collaboration between innovation subjects, the same investment of the innovation elements in academic institutes is more beneficial to increasing system heterogeneous knowledge than investment in enterprises. (2) The cultivation of innovative biotic factors in service institutions is conducive to the rapid interaction of heterogeneous knowledge among the innovation subjects. Still, it is not suitable for areas with higher homogeneous knowledge because high homogeneous environment can easily lead to intensified market competition. (3) The cultivation of the abiotic innovation environment is conducive to maintain stable high-speed growth of EIE heterogeneous knowledge increment over a long period. (4) Without considering the cost of environmental cultivation, cultivating biotic and abiotic environments at the same time is the most beneficial choice to EIE heterogeneous knowledge increment.

\section{Introduction}

With the scientific and technological revolutions from the Internet, enterprises face a more dynamic, complex, and uncertain competitive environment. How to improve the competitiveness to face the challenge is a severe test for enterprises at this stage. In the era of the knowledge economy, knowledge is considered a unique strategic resource [1], and rapid knowledge transfer is the key for enterprises to maintaining competitive advantage [2]. An IE (innovation ecosystem) construction is considered an important way for enterprises to acquire knowledge to maintain competitive advantage [3]. EIE (enterprise innovation ecosystem) is a new concept proposed in recent years, which integrates ecology and innovation system theory and applies the natural evolution law of natural ecological community to the economic management field [4]. To be specific, scientific research, enterprises, and other innovation subjects are the core subjects in the EIE, while the government, intermediary institutions, and users are considered as the support subjects. Through complex nonlinear interaction [4], knowledge, capital, and other resources within the IE are integrated, resulting in economical, social, and cultural effects that cannot be formed by a single enterprise [5]. Existing studies on the EIE [6] were mainly focused on the output of the innovation system, such as performance or value creation [7]. These studies emphasized the research on EIE from a strategic perspective [8,9]. Meanwhile, researchers paid more attention to the influence of microlevels such as entrepreneurship [10], knowledge 
[11], and technology [12] in EIE. Other studies [13] focused on the structure of the IE $[14,15]$ and the system's internal mechanism [16].

Although there are many studies on EIE, the following areas need to be improved: First, the process of knowledge resource flow and the law of knowledge increment in the EIE is less depicted. Considering the knowledge network structure and the internal and external sources of knowledge while ignoring the change of knowledge stock in the system cannot objectively reflect the nature of knowledge dissemination in the innovation system. Second, there is no further division of knowledge resources within the EIE. Knowledge in existing research is divided into explicit knowledge and implicit knowledge, with no further division of homogeneity and heterogeneity. Homogeneous knowledge is the basis for establishing cooperative relationships, but the increase of system knowledge depends on the interaction of heterogeneous knowledge. Third, there is a lack of quantitative analysis of the extent to which environmental elements within the EIE affect system output. The innovation subjects and the innovation environment elements are closely related to the whole. Ignoring the change of environmental factors, while only considering the role of the innovation subject in the system, will weaken the practical guiding significance of the research results.

Based on the aforementioned information, the research topic of this paper is the mechanism of heterogeneous knowledge increment of EIE and how the external environmental factors facilitate the increment of EIE knowledge. This paper uses the IE concept to define the subjects, environment, interactions, and influence relations among enterprises' innovation activities. Considering that the IE is a typical complex system, and knowledge increment is a "bottom-up" evolution process, a multiagent-based model is an appropriate approach to study such a complex system. To be specific, this paper builds a multiagent-based model for EIE heterogeneous knowledge increment. The model introduces biotic and abiotic environmental factors, identifies various scenarios, and analyzes the impact of external factors on system knowledge increment.

After the introduction, we sort the relevant theories in Section 2, introduce the applicable methods and put forward the hypothesis in Section 3, and present the empirical results and discussion in Section 4 and the research conclusions in Section 5. This paper enriches the existing theoretical achievements on the evolution of the increment of heterogeneous knowledge in EIE, fills the research gaps on the impact of innovation environment factors on heterogeneous knowledge increment, and provides a theoretical basis and reference for different regional governments to formulate enterprise innovation management policies.

\section{Theoretical Background}

2.1. Innovation Ecosystem. Moore [17] has put forward the concept of the innovation ecosystem for the first time and then proposed the concept of a business ecosystem. Adner [18] proposed EIE, regarding it as a complicated system consisting of firms who occupy different but interrelated ecological niches [19]. Enterprises in the EIE take knowledge creation as the core object and interact with stakeholders. EIE is a collaborative, interdependent, opening, and dynamic network system [20]. As a "life" system with dynamic, symbiotic, and sustainable development characteristics [21], EIE is also a collaborative mechanism; organizations use this cooperative mechanism to connect other organizations with the purpose of better coping with customers' requests to achieve value output [18]. The understanding of the concept of EIE is a deepening process. Many scholars have applied this theory to the empirical analysis about enterprises' innovation efficiency [22-24]. Scholars' understanding and definition of EIE are different from different perspectives, but the elemental composition and characteristics of EIE are consistent. Generally, the EIE is composed of innovation subject and innovation environment. There are interactions among innovation subjects, innovation subjects and innovation environment, and various resources flow through the interactions. Therefore, depending on the ecosystem theory and the current research results, this paper constructs the structure map of heterogeneous knowledge increment of EIE as shown in Figure 1. The system includes the subject, resource, and environment.

2.1.1. Innovation Subjects. Innovation subjects are the fundamental component of EIE. In Schumpeter's [25] innovation theory, the enterprise was the main subject, the scope of which is too narrow in today's situation. The field of innovation is broad, the subject of the invention is diverse, and people can use different standards to classify the innovation subjects. With the development of the innovation system's definition, scholars defined innovation subjects of IE as those innovation units that participate in the whole process of innovation from beginning to end and successfully put their ideas into practice. The formation of EIE is not a disorderly combination of subjects; each innovation subject has its niche. In this paper, according to the niche theory and nutrition supply mechanism, the innovation subjects in EIE are divided into producers and consumers; the positioning of producers and consumers will change according to the direction of the system's resource flow. That is, at different stages of the interaction between the system innovation subjects, the producer can also be a consumer and vice versa.

(1) Producers: universities and research institutes are the producers of original and basic knowledge in the EIE, while enterprises are the producer of applied knowledge. Producers usually combine consumers' knowledge demand and their knowledge stocks with the new knowledge in other disciplines to carry out knowledge reproduction. Universities and research institutes are skilled in basic knowledge and research methods and have a perfect talent pool but lack innovative capital and market experiences. Enterprises also have a certain amount of research departments, but in the current market background, most enterprises focus on progressive innovation; less investment is invested in basic research and 


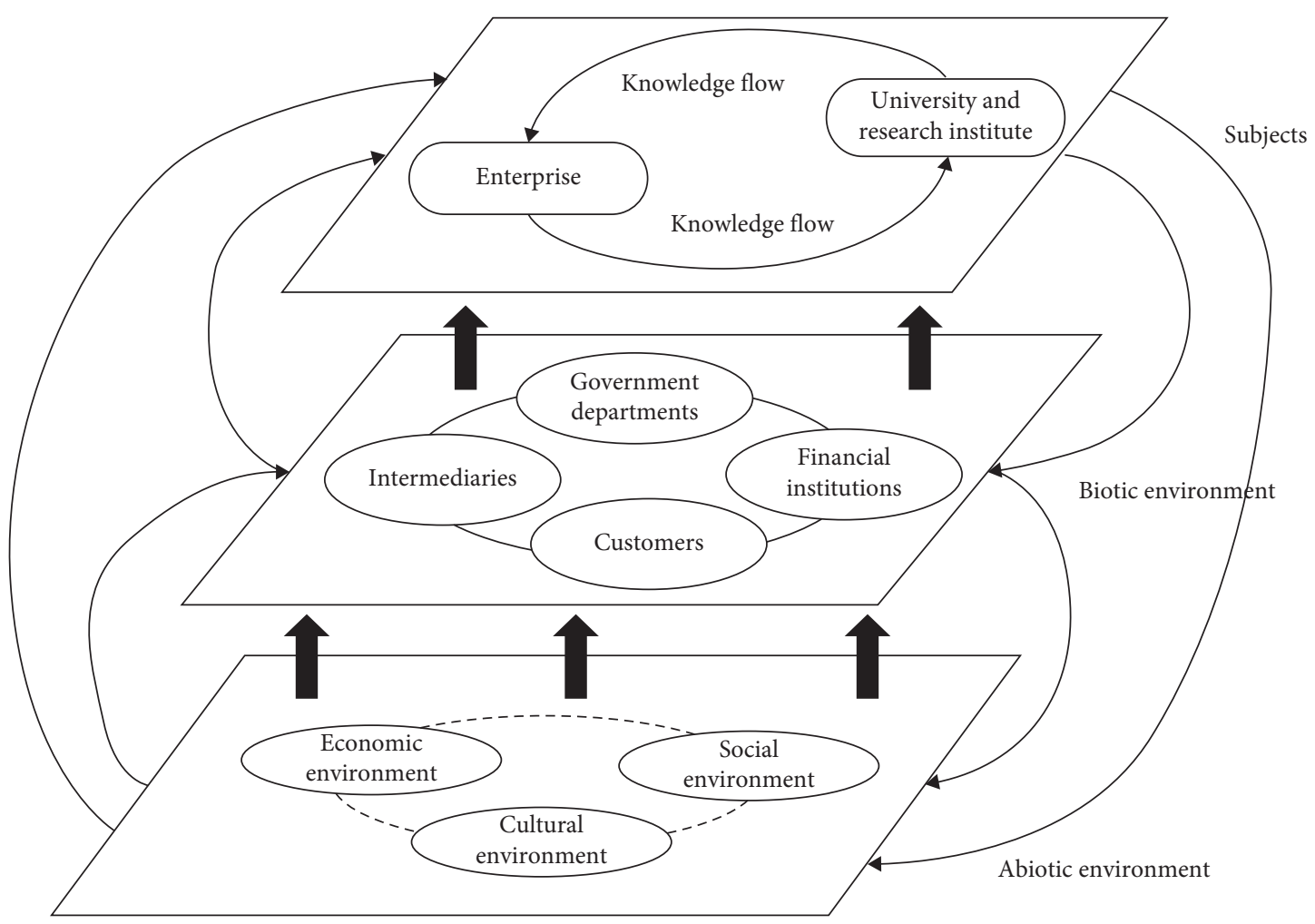

FIgURE 1: The structure of EIE (enterprise innovation ecosystem).

development, which lacks short-term economic benefits. Owing to these complementary needs, there is a driving force between enterprises and academic institutes to form a cooperation relationship of knowledge innovation.

(2) Consumers: the enterprises are the consumer of the original and basic knowledge in the EIE. The other innovation subjects in the system have direct or indirect contact with the enterprise. Enterprises transform knowledge into products and services, the products and services meet market demand. Those transform actions realize the value transformation of knowledge increment. Universities and research institutes are consumers of applied knowledge. Usually, the market presents the knowledge demand to the enterprises; in combination with demand, enterprises will implement their own "evolution" in the process of original and basic knowledge application. Then, these enterprises will feedback their new knowledge and new needs to the universities and research institutes. Meanwhile, universities and research institutes will start a new round of production after "internalization" of that feedback. These productionconsumption-reproduction-reconsumption processes of knowledge form a complete closed-loop of knowledge increment of EIE.

2.1.2. Resource. Knowledge is the most important resource in EIE [1]. The essence of innovation is the acquisition and creation of knowledge. The existence knowledge potential difference in innovation subjects [26] forms knowledge flow among the innovation subjects. According to different sources of knowledge, the knowledge can be divided into internal source knowledge and external source knowledge [27]. The internal source knowledge refers to the knowledge owned by subject itself, while the external source knowledge refers to the knowledge owned by other subjects. Besides, the knowledge flow is bound to be accompanied by the knowledge transformation, and the external source knowledge can be transferred to internal source knowledge at a certain rate. As there is heterogeneity between innovation subjects' ability, experience, concept, way of thinking, behavior habits, and personality characteristics, the knowledge produced by these innovation subjects has certain heterogeneity. Therefore, the knowledge can be further defined into heterogeneous knowledge and homogeneous knowledge. The more heterogeneous knowledge the system has, the stronger the ability to respond to external emergencies is and the more competitive it is in the market.

2.1.3. Environment. All innovation ecosystems have their corresponding special environment. The innovation environment provides the activity space for the innovation subject. For EIE, the external environment can be divided into "biotic" and "abiotic" environments [28]. The biotic environment includes stakeholders such as governments, intermediaries, financial services institutions, and users. Abiotic environment refers to economical, social, and cultural factors. Environmental factors that have an impact on innovation subjects are also referred as ecological factors. 
The change of each factor will cause the change of other related factors, and the multifactor change will have a comprehensive effect on the IE and its subjects. As each ecological factor has an "unbalanced" characteristic, each ecological factor plays a different role for different system subjects. The ecological factors that play the central role and determine the role are the leading factors. For example, governments are the most critical leading ecological factor of the EIE. They provide various rules, legal procedures, and codes of conduct, which will cultivate innovative ideas, stimulate innovation motivation, integrate innovative resources, and protect innovation achievements. As a leading ecological factor, the governments provide a powerful push to promote innovation and development.

2.2. Heterogeneous Knowledge. Heterogeneous resources are valuable scarce resources that are hard to imitate and replace. Knowledge is regarded as a unique resource in the era of knowledge economy [1]. Human resources and patents are the typical knowledge resources [29]. Heterogeneous resources constitute the endogenous source of the firms' core competitive advantage and the basis for creating rents [30]. Amabile et al. [31] believed that the heterogeneity of knowledge stems from the unavoidable differences in experience among team members. Tao et al. [32] defined heterogeneous knowledge as diversified knowledge and the information which is different from own knowledge field. The system can divide knowledge into homogeneous knowledge and heterogeneous knowledge according to the different characteristics of knowledge in content, hierarchy, and source. Due to differences in context, division of expertise, local inertia concerning knowledge acquisition, and the developmental path-dependence of knowledge, it is unrealistic to expect full knowledge homogeneity within enterprises [33]. From the perspective of knowledge base, knowledge heterogeneity helps not only to solve the crisis of innovation stagnation due to limited individual cognition but also the team to fully integrate heterogeneous knowledge resources from different subjects and form a unique product innovation advantage under the background of increasing innovation complexity [34]. Heterogeneous knowledge is an indispensable part of enterprises' innovation management and the key resource for companies to find new directions for development or explore new opportunities for product development [35]. Enterprises emphasize the combination and utilization of heterogeneous knowledge in the era of knowledge economy. For an enterprise to create value, effective management of heterogeneous knowledge is critical [36]. Above all, this paper defined heterogeneous knowledge as the knowledge owned by other innovation subjects, expanding its knowledge stock, improving the flexibility to cope with diversified needs, and enhancing its own and system innovation ability.

2.3. Mechanism of Knowledge Increment. In the era of knowledge economy, knowledge is the most important innovation resource. Rapid knowledge increment is the basis of efficient innovation within and between enterprises [37].
The concept of knowledge increment was first put forward by the American scholar Toffler in his book The Third Wave [38]. He pointed out traditional resources such as raw materials and capital were the factors of production in the first wave of science and technology. In contrast, information and knowledge were the core resources of the second wave of science and technology. He defined knowledge increment as the growth trend of knowledge in the process of evolution, derivation, differentiation, and expansion. Nonaka [39] defined that the knowledge increment of an organization can be transformed and valued through four circular models: socialization, externalization, combination, and internalization (SECI). Therefore, this paper defined the heterogeneous knowledge increment of the EIE as the following: enterprises collaborate with academic institutes, interacting with the innovation environment, through heterogeneous knowledge acquisition, internalization, propagation, elimination four stages to drive system's heterogeneous knowledge increment. Its system knowledge increment dual-cycle model is shown in Figure 2.

2.4. ABM (Agent-Based Method). EIE is a system with significant complex characteristics. A simple theoretical reasoning cannot reflect the complexity of the knowledge subject, the delay of knowledge flow, and the system evolution. In addition, it is not easy to evaluate the implementation effects of environmental element changes in EIE, so it will be very expensive to use experimental methods to analyze the research result. In other social science fields, similar dilemmas are often solved by systematic simulation methods. The agent-based model (ABM) has been suggested as an appropriate tool to solve the kind of complex system problems [40, 41]. Agent originated from artificial intelligence, which refers to an entity that has a certain degree of subjective initiative, can perceive changes in the environment and actively respond to the environment according to its own intentions. By simulating agents' behaviors and their interrelationships, ABM captures dynamic feedback from subsystems, which in turn describes and reflects the evolution of the entire complex system [41]. The analysis of evolutionary features improves the efficiency of the system's overall utilization. Simulation technology is widely used in biology, finance, society, energy, risk management, and so on. Garcia [42] indicated that ABM has potential for three areas about innovation: diffusion of innovations, organizational strategy, and knowledge/information flows. ABM has been widely applied for the field of innovation management in the existing research. Stummer and Kiesling [43] developed a commercial game simulation platform based on $\mathrm{ABM}$ theory, under the premise of considering social factors such as consumer heterogeneity and word-of-mouth transmission, helping students or junior managers to obtain first-hand experience in innovation and technology management. Sankar et al. [44] proposed an agent-based simulation scheme, simulating knowledge diffusion of the Indian Company Affiliation Network (ICAN), analyzing the impacts of board member behaviors on the knowledge flow of the enterprise. The flow of knowledge in the EIE is 




FIGURE 2: Double circulation of heterogeneous knowledge increment in EIE.

influenced by the innovation subject, innovation environment, and other factors. The heterogeneous knowledge increment in the system is a complex evolutionary process. The above analysis shows that ABM has great advantages in studying the heterogeneous knowledge increment of EIE.

\section{Methodology}

3.1. Framework of Agent-Based Model. Based on the analysis about the mechanism of knowledge increment among EIE, this paper built a multiagent-based model of the heterogeneous knowledge increment of EIE to study how different scenarios facilitate the heterogeneous knowledge increment. Therefore, we will explain our model in this paper from three aspects: simulation procedure, agents' attributes, and behavior rules.

3.1.1. Simulation Procedure. The multiagent-based model process was structured in three steps: model initiation, model runs, and model outputs (as shown in Figure 3). In the model initialization step, the agents were created and the basic attributes were set. When the agent-based model runs, the simulation process is completed by judging the type of knowledge, judging the proportion of heterogeneous knowledge of the agent, making knowledge transfer decisions. About the model output step, some data results at the system level were outputted, analyzed, and visualized.

3.1.2. Agents' Attributes. In this paper, the flow of knowledge resources in the model occurred between university research institutes and enterprises, so the simulation model contained two types of innovation subjects: the universities and research institutes agent $\left(\right.$ Agent $\left._{U}\right)$ and the enterprises $\left(\right.$ Agent $\left._{E}\right)$. There was a knowledge position difference between innovation subjects due to the different understanding about diversity knowledge and mastery degree of knowledge in subfields [45]. The existence of knowledge position difference promoted the formation of the knowledge sharing willingness of the innovation subjects. Knowledge sharing behaviors led to the flow of heterogeneous knowledge among different innovation subjects [46]. The heterogeneous knowledge transfer flow was similar to the biological resource "ingestion and absorption" process in natural ecosystems. Therefore, the activities related to knowledge transfer flow within the EIE were defined as four stages, namely knowledge acquisition, knowledge internalization, knowledge generation, and knowledge elimination. (1) Knowledge acquisition stage was corresponded to the "ingestion" of resources by organisms in the ecosystem. The amount of knowledge acquired was equal to the amount of knowledge shared by other innovative subjects in the system. (2) Knowledge internalization stage was referred to the "absorption" of resources by organisms in the ecosystem. The amount of knowledge internalized was equal to the amount of innovative knowledge captured after identification screening. (3) According to the theory of dynamic ability, each knowledge subject will have a certain degree of improvement in attribute ability in each development cycle [47] and some knowledge loss because it has not been used for a long. In other words, the transfer flow of heterogeneous knowledge created the process of "generation" of new knowledge and "elimination" of old knowledge. Innovation subjects reproduced knowledge based on their existing knowledge combined with internalized knowledge from other subjects. The amount of knowledge eliminated by innovation subjects is the part that cannot meet market demand. The above behaviors of the innovation subjects involve the following attributes: the knowledge stock of the innovation subject $\left(K_{*}\right)$, the ability to internalize the knowledge $\left(I_{*}\right)$, the ability to generate knowledge $\left(G_{*}\right)$, the elimination rate of the knowledge $\left(L_{*}\right)$, and the willingness of the innovation subject to share knowledge $\left(\gamma_{*}\right)$. Table 1 lists summarized parameters of the attributes involved in the model. 


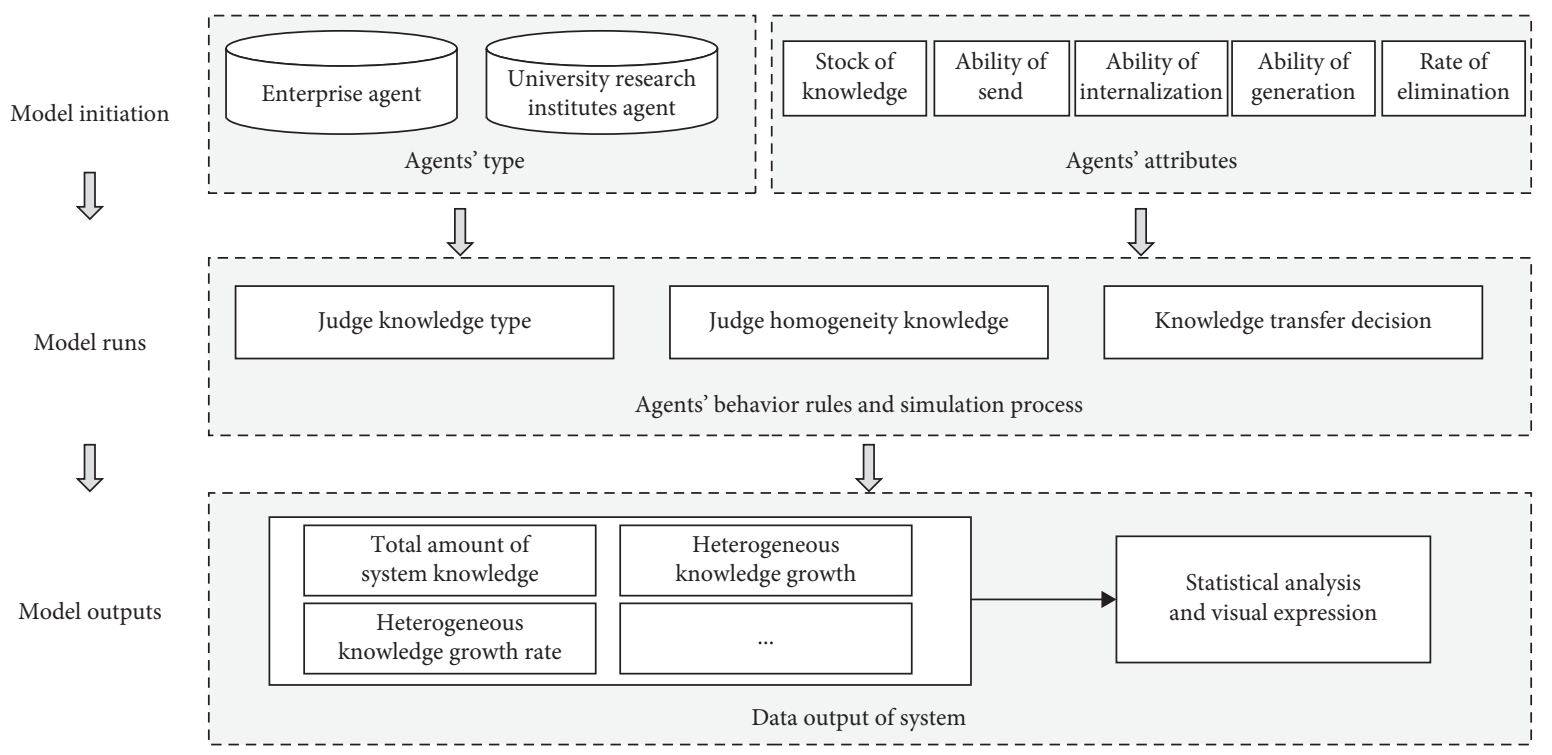

FIGURE 3: Simulation procedure of the agent-based model for heterogeneous knowledge increment of EIE.

TABLE 1: Innovation subjects' attributes parameters.

\begin{tabular}{lcccccc}
\hline Subjects & Knowledge stock & Internalization ability & Generation ability & Elimination rate & Share willingness & Share ability \\
\hline Agent $_{U}$ & $K_{U}$ & $I_{U}$ & $G_{U}$ & $L_{U}$ & $\gamma_{U}$ & $S_{U}$ \\
Agent $_{E}$ & $K_{E}$ & $I_{E}$ & $G_{E}$ & $L_{E}$ & $\gamma_{E}$ & $S_{E}$ \\
\hline
\end{tabular}

3.1.3. Behavior Rules. The interaction rules reflected the strategy of the innovation subject in the process of knowledge transfers in the EIE. The innovation subjects in the system were always constantly perceiving the surrounding environment, making judgments that are in line with their interests and then taking corresponding behavioral decisions. The strategies of each cycle were determined by combining the strategy state and interaction result of the previous cycle. Subjects' interactions facilitated the formation of the heterogeneous knowledge transfer flow and completed decision-making process shown in Figure 4. In this paper, heterogeneous knowledge interactions among agents were divided into four consecutive behaviors: knowledge acquisition, knowledge internalization, knowledge generation, and knowledge elimination. Table 2 lists all kinds of agents' interaction rules involved in the model.

(1) Acquisition: agents acquired heterogeneous knowledge due to the sharing behavior about knowledge of other innovation subjects. Therefore, the amount of heterogeneous knowledge acquired by Agent $_{U}$ in tick $t\left(K_{U, t}^{\text {acquisite }}\right)$ equals the amount of heterogeneous knowledge shared by the Agent ${ }_{E}$ at tick $t-1\left(K_{E, t-1}^{\text {Hete }}\right)$. The amount of heterogeneous knowledge acquired by Agent $_{E}$ in tick $t$ ( $\left.K_{E, t}^{\text {acquisite }}\right)$ equals the amount of heterogeneous knowledge shared by the Agent $_{U}$ at tick $t-1\left(K_{U, t-1}^{\text {Hete }}\right)$. The part of the knowledge stock of the innovation subject that excluded the system homogeneous knowledge $\left(K_{U E, t-1}^{\mathrm{Homo}}\right)$ is the heterogeneous knowledge held by itself $\left(K_{*, t-1}^{\text {Hete }}\right)$, and the knowledge that existing in every innovation subject was the homogeneous knowledge $\left(K_{U E, t-1}^{\mathrm{Homo}}\right)$ in the system. The innovation subjects will not share all of their heterogeneous knowledge due to the protection of core knowledge, cognitive differences, cultural situations, conflicts of interest, the goal not in harmony, and other reasons [45]. In other words, agents will not share $100 \%$ of heterogeneous knowledge. In the EIE system, there was a threshold of knowledge transfer $(\alpha)$; there is a decay in the willingness of the innovation subject to share knowledge when the homogeneous knowledge of the agent is higher than a certain proportion. Meanwhile, as the innovation hardware or software facilities were limited, the share ability $\left(S_{*}\right)$ of Agent $_{U}$ and Agent $_{E}$ will be limited, and only part of the shared knowledge can be transferred to other innovation subjects.

(2) Internalization: the producers and consumers in EIE often have communication barriers caused by information asymmetry [48], so it was impossible to fully internalize $K_{*}^{\text {acquisite }}$, agents with knowledge internalization rate $(I, I<100 \%)$. The digestion and absorption of resources need time, and the innovation subjects also need time to learn new knowledge from other subjects. Therefore, there was a lag period in the internalization process. Subjects need three ticks to transform the $K_{*}^{\text {acquisite }}$ into $K_{*}^{\text {internal }}$; in other words, the $K_{*}^{\text {acquisite }}$ acquired by the subjects in $t-3$ tick will not be internalized into their own knowledge stock until $t$ tick [49]. According to the theory of dynamic ability, the internalization ability $\left(I_{*}\right)$ will have a growth rate $\left(\beta_{*}\right)$ due to the 


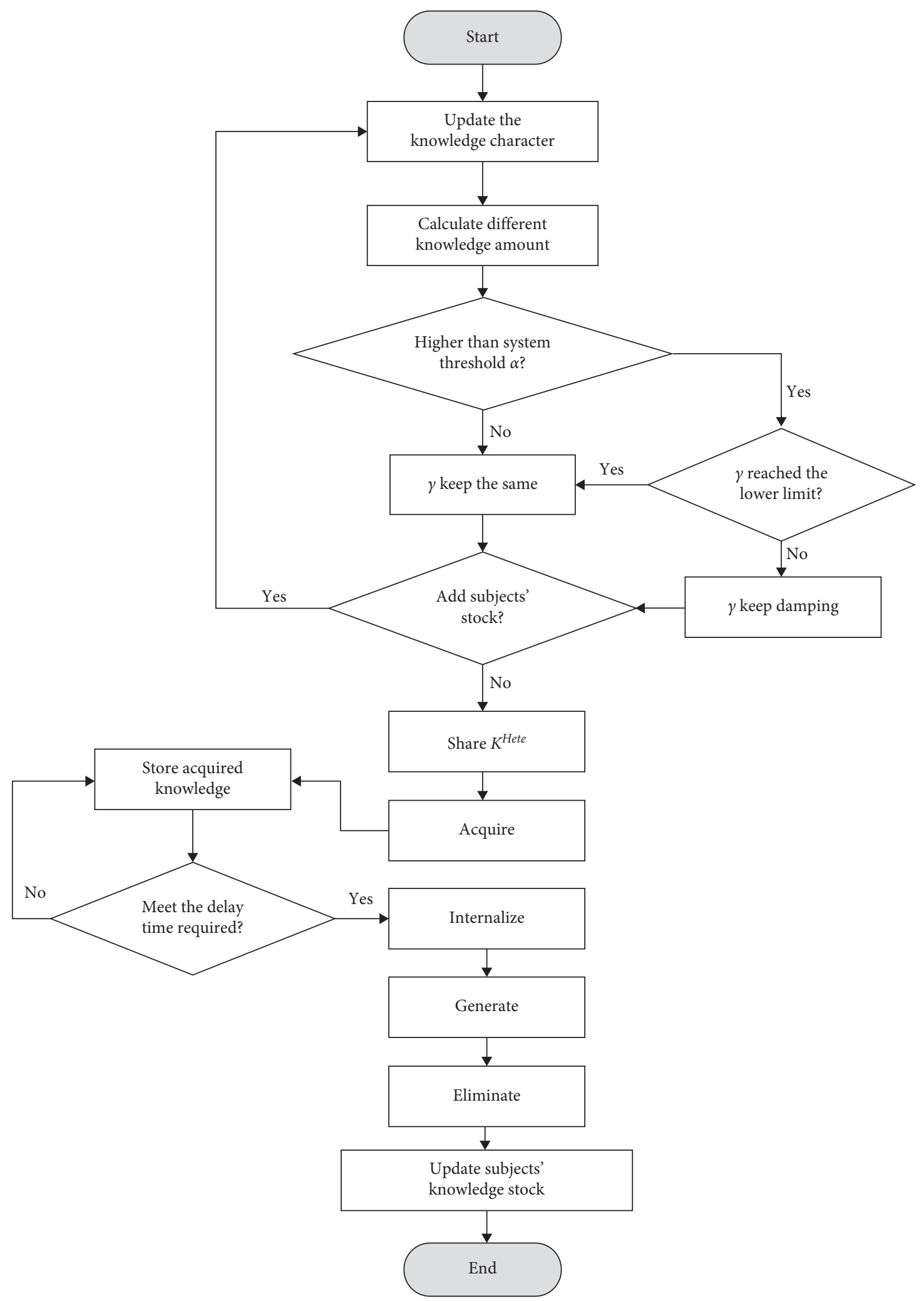

FIgURE 4: The flowchart of agents' decision-making. 
TABLE 2: Agents' behavior rules.

\begin{tabular}{|c|c|c|c|c|}
\hline Stage & \multicolumn{2}{|l|}{ Agent $_{U}$} & \multicolumn{2}{|l|}{ Agent $_{\mathrm{E}}$} \\
\hline Acquisition & $\begin{array}{c}K_{U E, t-1}^{\text {Homo }}=K_{E, t-1} \cap K_{U, t-1} \\
K_{U, t}^{\text {acquisite }}=K_{E, t-1}^{\text {Hete }} * S_{E, t} * \gamma_{E, t} \\
K_{E, t-1}^{\text {Hete }}=K_{E, t-1}-K_{U E, t-1}^{\text {Homo }}\end{array}$ & $\begin{array}{l}\text { (1) } \\
(2) \\
(3)\end{array}$ & $\begin{array}{c}K_{U E, t-1}^{\text {Homo }}=K_{E, t-1} \cap K_{U, t-1} \\
K_{E, t}^{\text {acquiste }}=K_{U, t-1}^{\text {Hete }} * S_{U, t} * \gamma_{U, t} \\
K_{U, t-1}^{\text {Hete }}=K_{U, t-1}-K_{U E, t-1}^{\text {Homo }}\end{array}$ & $\begin{array}{c}(1) \\
(10) \\
(11) \\
\end{array}$ \\
\hline Generation & $\begin{array}{c}K_{U, t}^{\text {internal }}=K_{U, t-3}^{\text {acquisite }} * I_{U, t} \\
I_{U, t}=I_{U, 0}+t * \beta_{U}\end{array}$ & & $\begin{array}{c}K_{E, t}^{\text {internal }}=K_{E, t-3}^{\text {acquisite }} * I_{E, t} \\
I_{E, t}=I_{E, 0}+t * \beta_{E}\end{array}$ & $\begin{array}{l}(12) \\
(13)\end{array}$ \\
\hline $\begin{array}{l}\text { Generation } \\
\text { Elimination }\end{array}$ & $\begin{array}{c}K_{U, t}^{\text {generate }}=\left(K_{U, t-1}+K_{U, t}^{\text {internal }}\right) * G_{U} \\
\quad K_{U, t}^{\text {eliminate }}=K_{U, t-1} * L_{U}\end{array}$ & $\begin{array}{l}\text { (6) } \\
(7)\end{array}$ & $\begin{array}{c}K_{E, t}^{\text {generate }}=\left(K_{E, t-1}+K_{E, t}^{\text {internal }}\right) * G_{E} \\
K_{E, t}^{\text {eliminate }}=K_{E, t-1} * L_{E}\end{array}$ & $\begin{array}{l}(14) \\
(15)\end{array}$ \\
\hline Increment & $\begin{array}{c}K_{U, t}^{\text {increment }}=K_{U, t}-K_{U, t-1} \\
K_{U, t}=K_{U, t-1}+K_{U, t}^{\text {internal }}+K_{U, t}^{\text {generate }}-K_{U, t}^{\text {eliminate }}\end{array}$ & $\begin{array}{l}\text { (8) } \\
(9)\end{array}$ & $\begin{array}{c}K_{E, t}^{\text {increment }}=K_{E, t}-K_{E, t-1} \\
K_{E, t}=K_{E, t-1}+K_{E, t}^{\text {internal }}+K_{E, t}^{\text {generate }}-K_{E, t}^{\text {elimnate }}\end{array}$ & $\begin{array}{l}(16) \\
(17)\end{array}$ \\
\hline Constraint condition & $\begin{array}{l}\text { Threshold tick }\left(t_{\text {Thre }}\right): K_{U}^{\mathrm{H}} \\
\gamma_{t}=\left\{\begin{array}{l}\gamma_{\text {upper limit }}, \quad t \leq t_{T} \\
\max \left\{\gamma_{\text {lower limit }}, \gamma_{\text {up }}\right.\end{array}\right.\end{array}$ & ${ }_{-1}^{o} / K_{U}$ & $\begin{array}{l}\geq \alpha \text { or } K_{U E, t-1}^{\mathrm{Homo}} / K_{E, t-1} \geq \alpha \\
\left.\left(t-t_{\text {Thre }}\right), \quad t>t_{\text {Thre }}\right\}\end{array}$ & (18) \\
\hline
\end{tabular}

stabilization agent cooperative relationship and the increasing knowledge stocks of the innovation subject itself.

(3) Generation: the innovation subjects generated new knowledge basis on the existing knowledge stocks in the last period $\left(K_{*, t-1}\right)$ and internalized knowledge in this period $\left(K_{*, t}^{\text {internal }}\right) . K_{U, t}^{\text {generate }}$ and $K_{E, t}^{\text {generate }}$ represented the amount of knowledge generated by university research institutes and enterprises at the $t$ tick. The iteration speed of incremental innovation knowledge and applied innovation knowledge of enterprises was higher than that of university research institutes $\left(G_{U, t}<G_{E, t}\right)$ because enterprises have close contact with the market and customers.

(4) Elimination: the rapid iteration of market demand resulted in the turnover and elimination of subjects' knowledge. The amount of knowledge lost by university research institutes and enterprises was based on the knowledge stock of the previous period $\left(K_{*, t-1}\right)$ with the loss coefficient $\left(L_{*}\right)$. Referred to the year of patent failure, the loss coefficient value was finally set at $0.4 \%$ each tick.

(5) Increment: the innovation subjects obtained knowledge increment in each simulation cycle due to 4 consecutive behaviors: knowledge acquisition, knowledge internalization, knowledge generation, and knowledge elimination. $K_{U, t}^{\text {increment }}$ and $K_{E, t}^{\text {increment }}$, respectively, represented the university research institutes and enterprises knowledge increment in $t$ tick.

(6) Constraint. Ecological system balance is a dynamic balance. The ecosystem keeps evolving in the direction of variety, structural complexity, and functional perfection in the natural environment until the ecosystem reaches a mature state. Akin to the natural ecosystem, the EIE heterogeneous knowledge increment behaviors have a dynamic balance stage. If the innovation subject's homogeneous knowledge stock exceeds proportional constraint $\left(K_{U E, t-1}^{\mathrm{Homo}} / K_{U, t-1} \geq \alpha\right.$ or $\left.K_{U E, t-1}^{\mathrm{Homo}} / K_{E, t-1} \geq \alpha\right)$, the innovation subject's willingness to share heterogeneous knowledge will continue to decline with a rate $(\delta)$ and eventually stabilize in the range ( $\max$ $\left\{\right.$ lower limit, upper limit $\left.-\delta *\left(t-t_{\text {Thre }}\right)\right\}$, tick $>$ Threshold tick), keeping the innovation system in a dynamic balance state.

3.2. Model Hypothesis. It is challenging to consider all the impact factors in one simulation model due to the complexity of the knowledge increment process, the complexity of the innovation subjects, and the realizability of the simulation. Therefore, some main assumptions were set to simplify the model and ensure the availability and credibility of results. The premises are as follows.

Hypothesis 1: the agents of EIE included university research institutes and enterprises. The positioning of producers and consumers will change according to the direction of systems' resource flow. That is, at different stages of the interaction between the system innovation subjects, the producer can also be a consumer, and vice versa.

Hypothesis 2: the demand from innovation subjects for heterogeneous knowledge resources was the internal driving factor of knowledge transfer. The system's homogeneous knowledge did not transfer among different agents.

Hypothesis 3: the cooperative relationship between university research institutes and enterprises was maintained continuously in the simulation cycle without disconnection.

Hypothesis 4: the interaction between different environmental factors was not considered when the biotic environmental factors and abiotic environmental factors simultaneously influence the innovation subjects. 
TABLE 3: Values of model parameters.

\begin{tabular}{lcccccccc}
\hline$R$ & $K^{\text {Hete }}$ & $K^{\text {Homo }}$ & $S$ & $I$ & $G$ & $L$ & $\gamma$ & \multicolumn{1}{c}{} \\
\hline Agent $_{U}$ & 500 & 100 & $60(\%)$ & $2(\%)$ & $2(\%)$ & $0.4(\%)$ & $80 \%$ & $0.5 \%$ \\
\hline Agent $_{E}$ & 200 & 100 & $60(\%)$ & $2(\%)$ & $3(\%)$ & $0.4(\%)$ & $80 \%$ & $0.5 \%$ \\
\hline
\end{tabular}

3.3. Parameters and Initialization. Table 3 lists summarized parameters involved in the initial model and their values in this paper. Those model parameters were important to build the multiagent-based model and necessary to format the agents' status and behaviors. There were two agents, Agent $_{U}$ and Agent $_{E}$, in the simulation model. The initial knowledge stock was set to 500 units and 200 units, and the initial homogeneous knowledge stock was set to 100 units. Heterogeneous knowledge sharing ability was $60 \%$. Agent ${ }_{U}$ 's internalization and generation capacity were $2 \%$ each simulation tick, and Agent $_{E}$ 's generation capacity was $3 \%$ each simulation time. Considering that the major policy planning cycle is 5 years in China, the model's simulation time was set to 60 ticks, each tick representing 1 month. $\alpha$ was set to $90 \%$, representing the threshold for heterogeneous knowledge sharing. $\gamma_{*}$ represented initial share willing and was set to $80 \%$. When subjects' homogeneous knowledge ratio reached the knowledge threshold, there was a 5\% decrease in the share willing per simulation cycle until reaching a minimum willingness of $10 \%$ to maintain the system's dynamic balance. Referred to the year of patent failure, the loss coefficient value was finally set at $0.4 \%$ each tick.

'This paper used Netlogo 6.0.4 simulation software platform to carry out simulation experiments. In order to avoid the influence of randomness on the experimental results, the average value of 100 simulation results was calculated. The simulation interface is shown in Figure 5. The simulation interface has three parts, the left are variables in the model, the middle is the interaction of innovation subjects when model running, and the right are plots of results.

3.4. Scenario Design. From the perspective of EIE, this paper analyzed the process of system's heterogeneous knowledge increment. The impact of innovation environment factors on heterogeneous knowledge increment was also a research point of this paper. We changed the values of variables related to the innovation environment to analyze the impact of the innovation environment on the increment of heterogeneous knowledge in the system. Different industries, different regions, different age groups, and different times all have effects on user demand. And the user demand changes on the impact of EIE are not general, so this paper finally selected the biotic environment factors (government, intermediary, and financial institutions) and the abiotic environment as three environmental factors for analysis. We made other parameters unchanged and adjusted the three parameters mentioned above to design eight different scenarios. The parameters' design is illustrated in Table 4. UTP represents the scenario of the impact caused by the government factor of the biotic environment on Agent $_{U}$. ETP represents the scenario of the impact caused by the government factor of the biotic environment on Agent $_{E}$. SP represents the scenario of the impact caused by the service institute factor of the biotic environment on Agent ${ }_{*}$. NEP represents the scenario of the impact caused by the abiotic environment factor on Agent $_{*}$. $\mathrm{X}+\mathrm{Y}$ represents that $\mathrm{X}$ scenario and $\mathrm{Y}$ scenario act on Agent ${ }_{*}$ simultaneously. For example, ETP + SP means the impact caused by the government factor, and the impact caused by the service institute factor will happen at the same time.

\subsubsection{Biotic Environment}

Government. The impact of government factor on EIE was reflected by increasing the stock of heterogeneous knowledge in the fixed cycle. Governments issued various laws and regulations, administrative rules, and development plans to guide innovation subject knowledge increment, while multiple types of innovation projects guide different subjects to participate in innovation [50]. Government's activities significantly increase the talent and technology investment in EIE [51]. The government's guidance is directed at different subjects, so the impacts of the government innovation environmental factors on university research institutes and enterprises were analyzed in different subscenario.

Intermediaries and Financial Institutions. The influences of intermediary and financial institution as abiotic environmental factors on the system were reflected by the increase of the knowledge internalization growth rate of innovation subject. Intermediaries and financial institutions can be summarized as service institutions. Knowledge producers' knowledge is mainly presented in patents, papers, research reports, and so on. Incubators, property rights trading centers, technology transfer centers, and other intermediary institutions through the in-depth processing of innovative knowledge integration, mining, and further deep-seated processing [51] improve consumers' heterogeneous knowledge absorption, application, and re-innovation efficiency. Financial institutions introduce financial support for technology research and development and speed up research and development $[52,53]$.

\subsubsection{Abiotic Environment}

Economic, Social, and Cultural Factors. Impacts of abiotic environmental factors on EIE heterogeneous knowledge increment mainly were reflected by the subjects' willingness to share knowledge. A developed economic environment is conducive to enterprise innovation institution-building and provides economic support for implementing the policy system. Besides, a developed economic environment will bring stable market demand. A good social environment is essential for attracting innovative talent. The formation of an active cultural environment will form a positive spirit of innovation. Thus, economic, social, and cultural factors constitute indirect drivers of knowledge increment in the EIE. 

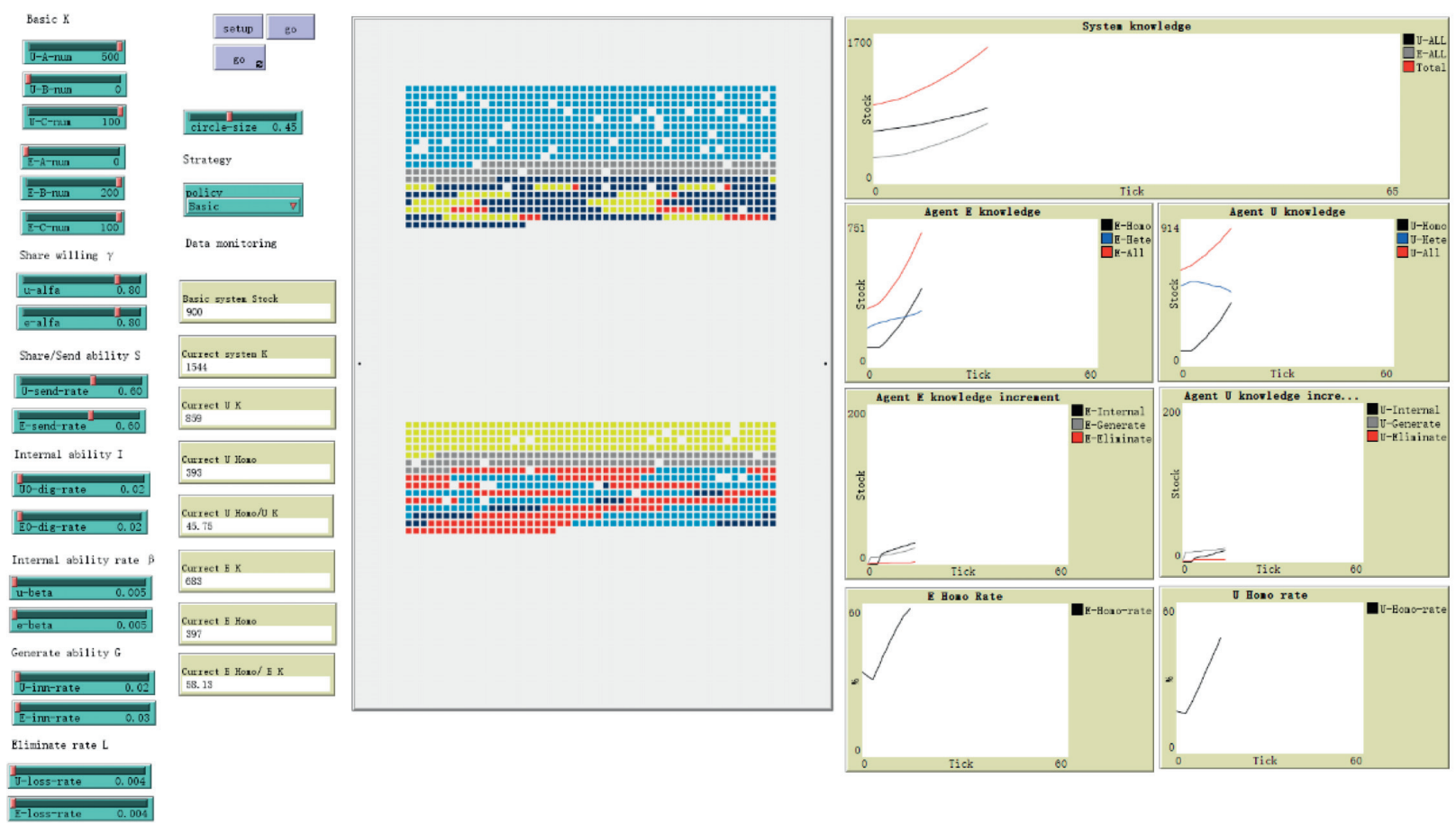

FIgURE 5: Netlogo 6.0.4 simulation platform.

TABle 4: Parameters' design for eight scenarios.

\begin{tabular}{|c|c|c|c|c|}
\hline Scenario & Agent $_{U}^{\text {Hete }}$ & Agent $_{\mathrm{E}}^{\text {Hete }}$ & $\beta$ & $\gamma$ \\
\hline Basic & 500 & 200 & $0.5 \%$ & $80 \%$ \\
\hline UTP & Add 100 units/12 ticks & - & - & - \\
\hline ETP & 一 & Add 100 units/12 ticks & - & - \\
\hline SP & - & - & $1 \%$ & - \\
\hline NEP & - & - & - & $90 \%$ \\
\hline $\mathrm{ETP}+\mathrm{SP}$ & - & Add 100 units/12 ticks & $1 \%$ & - \\
\hline $\mathrm{SP}+\mathrm{NEP}$ & - & - & $1 \%$ & $90 \%$ \\
\hline $\mathrm{ETP}+\mathrm{NEP}$ & - & Add 100 units/12 ticks & 一 & $90 \%$ \\
\hline $\mathrm{ETP}+\mathrm{SP}+\mathrm{NEP}$ & - & Add 100 units/12 ticks & $1 \%$ & $90 \%$ \\
\hline
\end{tabular}

"-" denotes the values of the parameters are not changed, the same with the basic scenario.

3.4.3. Composite Environment. With composite environment reflected by subjects' heterogeneous knowledge stock added, the increase of the knowledge internalization growth rate of innovation subject and the subjects' willingness to share knowledge changed simultaneously. The ecosystem is a system of nonlinear interaction between biological subjects and biological environments. Only considering the individual factor cannot objectively look at the changes of the whole. Therefore, this paper considered the impacts of multienvironment simultaneous changes, that is, considering the effect of the concurrent evolution of biotic environment and abiotic innovation environment on the system.

\section{Results and Discussion}

4.1. Basic Scenario of EIE's Heterogeneous Knowledge Increment. Figures 6 and 7 illustrate the simulation results of the basic scenario of the heterogeneous knowledge increment simulation model. In this basic scenario, the evolution trend of the heterogeneous knowledge increment of different agents in the EIE without being affected by the external environmental factors was observed. The characteristics of the heterogeneous knowledge increment of the innovation subject were analyzed according to the results of the data simulation in some essential time nodes.

The results indicated that from the overall perspective, comparing tick 0 with tick 4 , it can be found that the heterogeneous knowledge obtained from other subjects has not been internalized into its knowledge stock until the 3 ticks later, due to the lag of the internalization ability. At end of the tick 24, the heterogeneous knowledge added through the knowledge interaction process $\left(K_{t}^{\text {internal }}\right)$ to be accounted for more than half of the total value add-on of heterogeneity knowledge $\left(K_{t}^{\text {hete-add }}\right)$. Besides, the heterogeneity knowledge generated $\left(K_{t}^{\text {generate }}\right)$ based on the knowledge stock has 




Figure 6: Agent ${ }_{U}$ heterogeneous knowledge increment evolution.

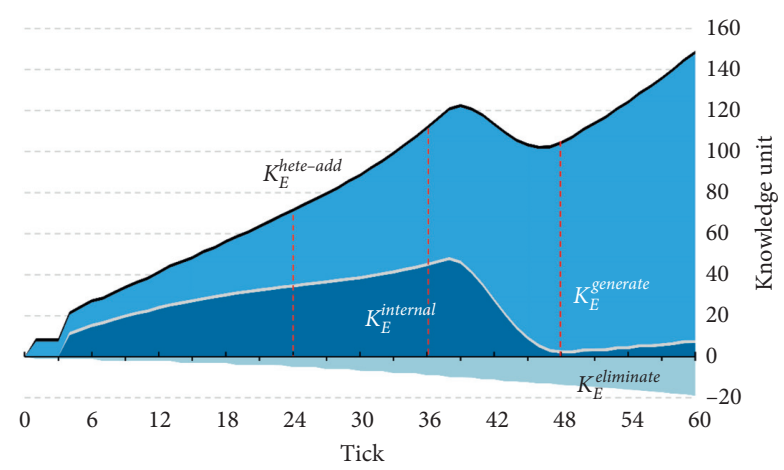

Figure 7: Agent $_{E}$ heterogeneous knowledge increment evolution.

produced a boost to the system knowledge increase. During the period from tick 25 to tick $36 \mathrm{~s}, K_{25 t h-36 t h}^{\text {hete-add }}$ was comparable to the total amount of $K_{1 t h-24 t h}^{\text {hete-add }}$, indicating that the rate of heterogeneity knowledge increment of EIE was significantly accelerating with the increase of innovation subjects' knowledge stock, due to the stability of the cooperative innovation relationship, and the ability to internalize heterogeneous knowledge enhanced. During the period from tick 36 to tick 48, accompanying with the innovation subjects' homogeneous knowledge stock exceeds proportional constraint, the willingness to share the innovation subjects' heterogeneous knowledge continuously decreased, the increment amount of $K_{t}^{\text {hete-add }}$ slowed down, and $K_{t}^{\text {generate }}$ based on its knowledge stock became the main driving force of $K_{t}^{\text {hete-add }}$. During the period from tick 48 and tick 60, the total amount of $K_{t}^{\text {hete-add }}$ gradually increased, $K_{t}^{\text {generate }}$ became the central part of knowledge increment in each tick, while the interaction ratio of heterogeneous knowledge between the innovation subjects remained at a relatively stable level, and $K_{t}^{\text {internal }}$ contributed relatively little to the $K_{t}^{\text {hete-add }}$. With the growth of the innovation subjects' knowledge stock, the amount of knowledge elimination $\left(K^{\text {eliminate }}\right)$ increased with passage of time. From the individual perspective, comparing the heterogeneous knowledge increment process between university research institutes and enterprises, it can be known that the processes of increment are similar, but the $K_{E}^{\text {hete-add }}$ were higher than $K_{U}^{\text {hete-add }}$, which was mainly due to the rapid iteration rate of enterprises' application innovation.
4.2. Multiple Scenarios of EIE's Heterogeneous Knowledge Increment. The parameters related to the EIE model are adjusted in order to form different innovation environments. Figures 8 and 9 illustrate the comparison of simulation results under multiple scenarios.

4.2.1. Systems' Perspective. The results (as shown in Figure 8) indicated that (1) there were great distinctions in the impacts caused by the different environmental factors' improvement on the heterogeneous knowledge increment in EIE. Except the change of service institutions' factors that have a negative effect, all the other strengths of innovative environmental factors have a significant positive effect on heterogeneous knowledge increment in EIE. The cultivation of service institutions accelerated the proportion of homogeneity and made the decay of knowledge sharing willingness of the innovation subject. The strengthening of service institutions made the system reach the threshold of knowledge homogeneity ratio in a short period of time. The strengthening of service institutions was conducive to the in-depth excavation and efficient integration of heterogeneous knowledge of innovative subjects, which promoted the exchange of heterogeneous knowledge of the subject. (2) In separate scenarios, the cultivation of the abiotic environment has a better promotion effect than the biotic environment for the system knowledge increment. The strengthening of abiotic environmental factor has increased the share willingness of subjects and lengthened the share willingness decay after the system has reached the threshold. So, these strengthened strategies will help the system keep a high level of interaction in the simulation period. (3) Most multienvironment scenarios have a better promotion effect than the effect of separate scenarios on system's heterogeneous knowledge increment. The role of composite environment cultivation in innovative ecosystems was not simple linear addition, so there is shown a " $1+1>2$ " resonance effect. (4) The system knowledge increment was optimal when biotic and abiotic environmental factors were simultaneously effecting on the system.

4.2.2. Subjects' Perspective. The results (as shown in Figure 9) indicated that (1) in the multi-scenarios, $K_{U}^{\text {internal }}$, which is observed from enterprises by university research institutes, was greater than $K_{E}^{\text {internal }}$ which is observed by enterprises from university research institutes. The amount of $K_{E}^{\text {generate }}$ in the simulation cycle was more than that of $K_{U}^{\text {generate }}$, due to close relationship between enterprise and market; these relationships help the enterprise realize the rapid iteration of application knowledge. (2) In the cultivation of biotic environment factors, the same investment of the innovative elements in university research institutes has a greater effect on the system than that of enterprise to the system knowledge increment. As a typical complex system, the value add-on of EIE presented nonlinear characteristics. Besides, the larger the initial knowledge stock of the subject, the more obvious the phenomenon of "emerging" of the system heterogeneous knowledge value add-on. University 


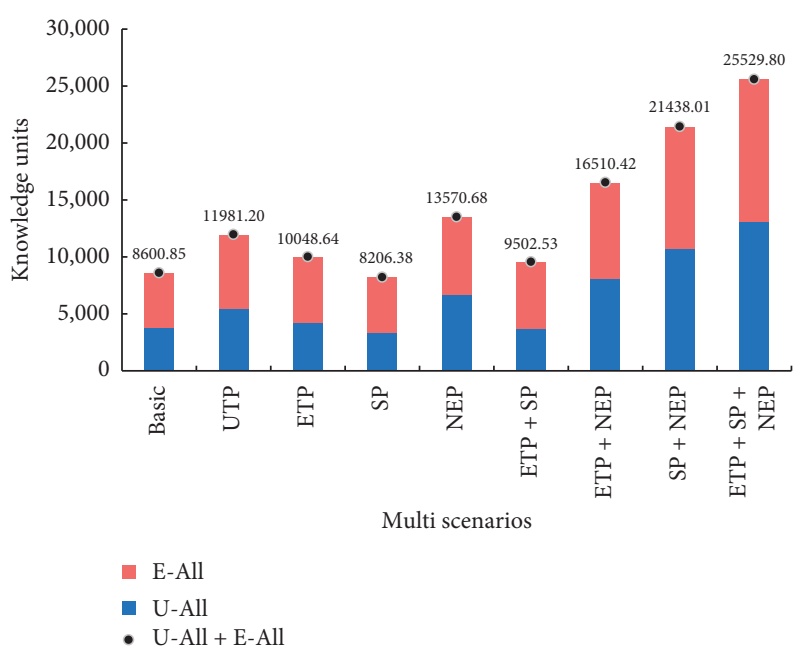

Figure 8: The trend of heterogeneous knowledge increment of EIE in multi-scenarios.

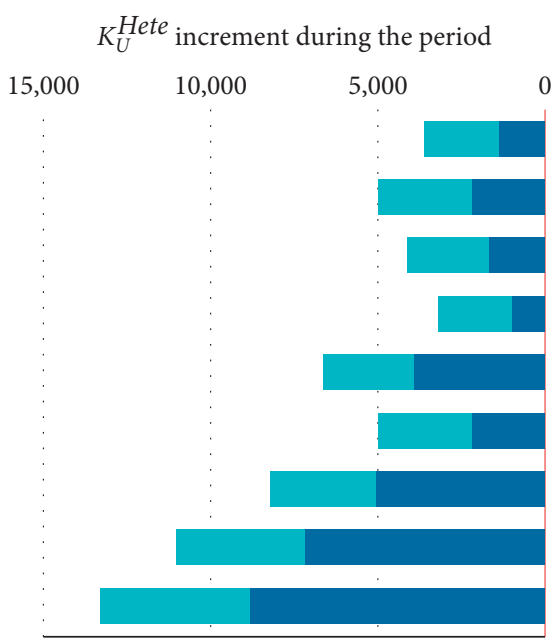

Knowledge generation

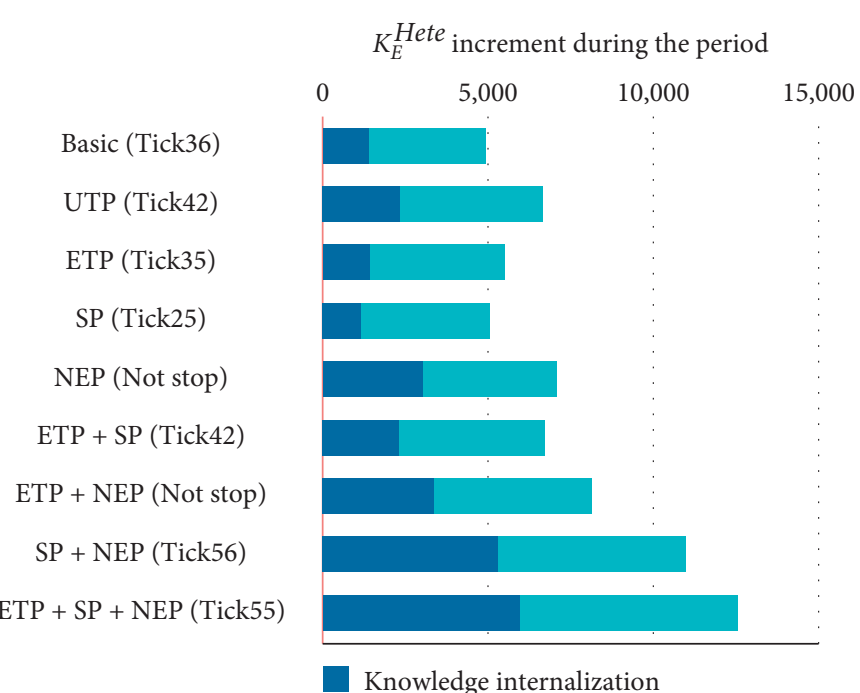

Knowledge internalization

Figure 9: The trend of heterogeneous knowledge increment of innovation subjects in multi-scenarios.

research institutes as the origin of innovative knowledge, and the initial heterogeneous knowledge was greater than that of enterprises, so it was more efficient to invest the same amounts of resources in university research institutions than enterprises. (3) In the scenario of biotic environment cultivation, the cultivation of service institutions has an inhibitory effect on the value add-on of the system. The strengthening of service institutions accelerated the exchange speed of heterogeneous knowledge between the innovation subjects. In tick 25, subjects reached the threshold of knowledge sharing willingness, resulting in the EIE innovation subject maintaining a low-level knowledge sharing willingness in other periods. (4) The scenario of abiotic environment cultivation has played a good role in the steady growth of heterogeneous knowledge of EIE during the simulation cycle. In the innovative environment strategy "NEP" and "ETP + NEP", the subjects have not reached the threshold $\alpha$, resulting in a decline in the willingness of heterogeneous knowledge sharing. In "SP + NEP" and
"ETP + SP + NEP" scenarios, the subjects have not reached the point until tick 56 and tick 55 . The later the system reached the threshold $\alpha$, the higher level of innovation subjects' heterogeneous knowledge interaction been maintained during the simulation period.

\section{Conclusion}

5.1. Main Finding. Innovation is the main driving force for enterprises to maintain market competitiveness. In the era of the knowledge economy, knowledge is regarded as the most important strategic resource. Heterogeneous knowledge is the basis for enterprises to achieve rapid innovation in response to market demand. The construction of an innovative ecosystem is considered to an effective way to obtain heterogeneous knowledge. Consequently, the topic of the heterogeneous knowledge increment in EIE gained centrality in the agenda of researchers and enterprise managers. Based on the ecology theory, this paper analyzed the 
characteristics of the innovation subject and the rules of the heterogeneous knowledge interaction between innovation subjects. Then, we proposed a multiagent-based model. By combining the three parameters: subjects' knowledge stock, the growth rate of internalization ability, and the share willingness, this paper designs eight different innovation environment scenarios, consisting of biotic and abiotic environments, to explore the dynamic impacts of these factors on the EIE heterogeneous knowledge increment. The conclusions drawn from the numerical experiments are as follows.

First, the process of heterogeneous knowledge increment in EIE showed prominent nonlinear characteristics. There was a lag in the internalization process due to internal knowledge need time. In the early stages of simulation, the knowledge interaction action was the primary source for subjects' heterogeneous knowledge increment. Still, knowledge generation action has played the primary boost for subjects' heterogeneous knowledge increment with the simulation time going. In the late stage of simulation, the proportion of system's homogeneous knowledge reached the threshold, the willingness of innovation subject to share decayed, and the knowledge added through the knowledge generation process that far exceeded interaction process became the absolute driving force of the system knowledge increment.

Second, there were significant distinctions in the impacts caused by different environmental factors on the heterogeneous knowledge increment of EIE. Most multienvironment scenarios have a better promotion effect than the effect of separate scenarios on the system's heterogeneous knowledge increment. In separate scenarios, the cultivation of the abiotic environment has a better promotion effect than the biotic environment. The strengthening of service institutions' factors has a negative effect on the increment. The same investment of the innovative elements in university research institutes has a more significant effect on the system than that of an enterprise.

5.2. Theoretical and Empirical Implications. This paper is associated with the field of EIE and knowledge management. Research results have shown theoretical contributions to previous literature from three aspects. First, this paper constructed the EIE model from three parts: innovation subject, innovation resource, and innovation environment. Existing researches pay close attention to the system boundary difference between IE and EIE [54]. This paper further focuses on the characteristic of innovation elements within the system. The innovation subjects are further divided into producers and consumers, and the innovation environment is further divided into biotic and abiotic environments. Second, this paper divided the properties of innovative resources (knowledge) into homogeneity and heterogeneity. It also considered the influence of two-way heterogeneous knowledge flow between innovation subjects on the increase of system knowledge. The mainstream classification criteria of dividing knowledge in existing research are explicit and tacit. Thus, heterogeneous knowledge management research carries existing research further. Third, this study plays an active role in the development of the EIE model. Theoretical analysis and case study are mainstream research methods of EIE [34]. The application of modeling and computational experiments is still obviously inadequate [6], so these results cannot describe the complex characteristics of EIE visually. The multiagent-based model built in this paper makes up for this deficiency.

This paper also has positive implications for policymakers and enterprise managers. First, according to the research results of this paper, different strategies of innovation environment cultivation will have different effects on the heterogeneous knowledge increment of EIE. Policymakers need to formulate appropriate policy tools according to the resource endowment of the region. Second, while there is a cost in cultivating an innovative environment, policymakers need to choose the strategy to realize the greatest marginal utility according to enterprises' demand. In addition, combining with the different characteristics of knowledge increment at different stages, which is reflected in this paper, enterprises need to carry dynamic interaction with the innovation environment according to their development cycle changes and strive for the best environmental space for their development.

5.3. Limitations and Future Research. Despite the university research institutes and core enterprises as the innovation subjects of EIE in numbers of studies, there is still insufficient evidence, concerning the upstream, midstream, and downstream enterprises in the connection system. Different sizes of enterprises caused significant differences in innovation efficiency. SME (small and medium-sized enterprises) showed a higher tendency to innovate. In addition, different network structures among innovation subjects have impact on the efficiency of knowledge transfer in the EIE $[55,56]$. All in all, scholars and business managers need to expand the innovation subject in the EIE to a broader range.

Regarding the diversity of user demands, the impacts on the EIE are not general, and this paper does not considered the user environment factor in the simulation model. As the entry gate to the marketplace, the effect of the user on the direction of enterprise innovation is becoming more and more prominent [57]. More efforts need to be made to systematically include the user in the ecosystem, given its increasing importance [58].

Although the parameters' values in the simulation model of this paper were based on existing researches and realistic situations, further research needs to be analyzed with specific enterprise cases to improve scientificity and rationality.

5.4. Policy Recommendations. According to the positive implications of this paper, considering the current situation of enterprise innovation, the following policy suggestions have been proposed for policymakers and enterprise managers:

(1) The cultivation of an abiotic environment has a better effect on the EIE heterogeneous knowledge increment 
than the cultivation of a biotic environment. In the stage of rapid economic development in China, many industries are still in the introduction period or growth period. Most local enterprises rely on the technology transfer of multinational companies to occupy the dominant position in the market. The domestic enterprises' willingness to innovate is reluctant due to the weak enforcement of domestic intellectual property protection. The government needs to create a good political, economical, social, and cultural environment to improve the willingness of domestic enterprises to innovate and promote the EIE heterogeneous knowledge increment. The sustainable and stable increment of heterogeneous knowledge will provide winning elements to enterprises in future market competition.

(2) In the cultivation of an abiotic environment, the investment of innovation elements of basic knowledge and basic technology into the university and research institutes is more beneficial to the system development than that of the enterprises. The local government should encourage cooperation in the field of R\&D (research and development) between university research institutes and enterprises. By tracking the progress of cooperation, the policymaker should adjust relevant policies promptly and promote the efficient application of innovative results. The cultivation of service institutions is conducive to the rapid exchange of heterogeneous knowledge. Still, in regions with high homogeneity, the cultivation of excessive intermediary service institutes will increase the extra competition in the market, which is not conducive to the benign development of the IE.

(3) Considering the cost of environmental factors cultivation, the government should choose different combinations for different types of industries. The industries in a strategic global position, the government should cultivate two types of environmental factors simultaneously without cost consideration, promoting the rapid growth of the system knowledge stock. When the cost becomes a certain constraint, simultaneous cultivation of service institutions and the abiotic environment factors is the optimal choice. When the industries have strong market demand while the knowledge heterogeneity demand is low, the strengthening of service institutions will be the most complementary innovation environment cultivation strategy.

\section{Data Availability}

The primary data used to support the findings of this paper are available from the authors upon request (zqwang@ hhu.edu.cn).

\section{Conflicts of Interest}

The authors declare that they have no conflicts of interest.

\section{Authors' Contributions}

R.W. wrote the original draft, conceptualized the study, and performed formal analysis. Z.W. developed the methodology, performed validation, provided software, and corrected the grammar. Q.S. performed project administration and was responsible for funding acquisition. All the authors have read and agreed to the published version of the manuscript.

\section{Acknowledgments}

The authors would like to express their gratitude to Shanqing Huang, Jingle Kang, and Shiliang Yang for their suggestion about editing and methodology. This research was funded by National Natural Science Foundation of China (grant nos. 71771161 and 71801133).

\section{References}

[1] R. Grover and T. M. Froese, "Knowledge management in construction using a socioBIM platform: a case study of AYO smart home project," Procedia Engineering, vol. 145, pp. 1283-1290, 2016.

[2] P. A. Nylund, X. Ferras-Hernandez, and A. Brem, "Strategies for activating innovation ecosystems: introduction of a taxonomy," IEEE Engineering Management Review, vol. 47, no. 4, pp. 60-66, 2019.

[3] H. Tang, Z. Ma, J. Xiao, and L. Xiao, “Toward a more efficient knowledge network in Innovation ecosystems: a simulated study on knowledge management," Sustainability, vol. 12, no. 16, p. $6328,2020$.

[4] X. Wang, X. Li, and B. Guo, "Research on the optimization of cultural industry innovation ecosystem based on SD model: a case study of Shanghai," Science Technology Progress and Policy, vol. 31, no. 24, pp. 64-70, 2014.

[5] W. Yang, J. Liu, L. Li, Q. Zhou, and L. Ji, "How could policies facilitate digital transformation of innovation ecosystem: a multiagent model," Complexity, vol. 2021, Article ID 8835067, 19 pages, 2021.

[6] L. A. d. V. Gomes, A. L. F. Facin, M. S. Salerno, and R. K. Ikenami, "Unpacking the innovation ecosystem construct: evolution, gaps and trends," Technological Forecasting and Social Change, vol. 136, pp. 30-48, 2018.

[7] D. Trabucchi and T. Buganza, "Fostering digital platform innovation: from two to multi-sided platforms," Creativity and Innovation Management, vol. 29, no. 2, pp. 345-358, 2020.

[8] D. P. Hannah and K. M. Eisenhardt, "How firms navigate cooperation and competition in nascent ecosystems," Strategic Management Journal, vol. 39, no. 12, pp. 3163-3192, 2018.

[9] J. Jansson, J. Nilsson, F. Modig, and G. Hed Vall, "Commitment to sustainability in small and medium-sized enterprises: the influence of strategic orientations and management values," Business Strategy and the Environment, vol. 26, no. 1, pp. 69-83, 2017.

[10] E. J. Malecki, "Entrepreneurship and entrepreneurial ecosystems," Geography Compass, vol. 12, no. 3, Article ID e12359, 2018.

[11] G. Santoro, D. Vrontis, A. Thrassou, and L. Dezi, “The internet of things: building a knowledge management system for open innovation and knowledge management capacity," 
Technological Forecasting and Social Change, vol. 136, pp. 347-354, 2018.

[12] R. Adner and R. Kapoor, "Innovation ecosystems and the pace of substitution: Re-examining technology S-curves," Strategic Management Journal, vol. 37, no. 4, pp. 625-648, 2016.

[13] R. Zhan, H. Wang, and X. Meng, "Review and prospect on enterprise innovation ecosystem," Science of Science and Management of S.\& T.vol. 41, no. 05, pp. 179-197, 2020.

[14] C. Sun and W. Jiang, "The structure and collaborative mechanism of firm-level innovation ecosystem," Studies in Science of Science, vol. 37, no. 7, pp. 1316-1325, 2019.

[15] Z. Wang, Q. Li, and X. Bao, "Responsibility and coordinated development of government university-entrepreneur-society under the innovation and entrepreneurship ecosystem-based on the comparative study of the United States, Germany and Japan," Forum on Science and Technology in China, vol. 09, pp. 182-188, 2019.

[16] Z. Ou, Z. Zhu, M. Xia et al., "The symbiotic evolution model of the innovation ecosystem and its simulation analysis," Scientific Research Management, vol. 38, no. 12, pp. 49-57, 2017.

[17] J. F. Moore, "Predators and prey: a new ecology of competition," Harvard Business Review, vol. 71, no. 3, pp. 75-86, 1993.

[18] R. Adner, "Match your innovation strategy to your innovation ecosystem," Harvard Business Review, vol. 84, no. 4, pp. 98-148, 2006.

[19] I. Marco and L. Roy, "Strategy as ecology," Harvard Business Review, vol. 82, no. 3, pp. 68-78, 2004.

[20] S. Jiang, P. Lv, and J. Chen, "Literature review on enterprise innovation ecosystem: from perspective of core enterprise," Journal of Technology Economics, vol. 34, no. 07, pp. 18-23, 2015.

[21] X. Liu and G. Zhang, "Innovation ecoystem: exploring the nature of inovation-divern and innovation paradigm change," Science \& Technology Progress and Policy, vol. 33, no. 20, pp. 1-6, 2016.

[22] S. Jiang, Y. Hu, and Z. Wang, "Core firm based view on the mechanism of constructing an enterprise innovation ecosystem: a case study of Haier Group," Sustainability, vol. 11, no. 11, p. 3108, 2019.

[23] Y. Chen, Y. Chen, Y. Guo, and Y. Xu, "Research on the coordination mechanism of value cocreation of innovation ecosystems: evidence from a Chinese artificial intelligence enterprise," Complexity, vol. 2021, Article ID 7629168, 16 pages, 2021.

[24] P. A. Nylund, A. Brem, and N. Agarwal, "Innovation ecosystems for meeting sustainable development goals: the evolving roles of multinational enterprises," Journal of Cleaner Production, vol. 281, Article ID 125329, 2021.

[25] J. A. Schumpeter and U. Backhaus, The Theory of Economic Development, Springer US, Boston, MA, USA, 2003.

[26] Y. Daiso and Z. Line, "Influence of knowledge potential difference on intellectual property risk in industry-universityinstitute cooperation," Science Research Management, vol. 39, no. 2, pp. 75-85, 2018.

[27] L. Ardito, A. Messeni Petruzzelli, L. Dezi, and S. Castellano, "The influence of inbound open innovation on ambidexterity performance: does it pay to source knowledge from supply chain stakeholders?" Journal of Business Research, vol. 119, pp. 321-329, 2020.

[28] D. Jackson. "What is an innovation ecosystem," (accessed on: 26/03/2015). Available online:https://www.researchgate.net/ publication/266414637_What_is_an_Innovation_Ecosystem.
[29] Y. Su and Y.-Q. Yu, "Spatial agglomeration of new energy industries on the performance of regional pollution control through spatial econometric analysis," Science of The Total Environment, vol. 704, Article ID 135261, 2020.

[30] J. Barney, "Firm resources and sustained competitive advantage," Journal of Management, vol. 17, no. 1, pp. 99-120, 1991.

[31] T. M. Amabile, R. Conti, H. Coon, J. Lazenby, and M. Herron, "Assessing the work environment for creativity," Academy of Management Journal, vol. 39, no. 5, pp. 1154-1184, 1996.

[32] C. Tao, Y. Qu, H. Ren, and Z. Guo, "The influence of interenterprise knowledge heterogeneity on exploratory and exploitative innovation performance: the moderating role of trust and contract," Sustainability, vol. 12, no. 14, p. 5677, 2020.

[33] C. Schmickl and A. Kieser, "How much do specialists have to learn from each other when they jointly develop radical product innovations?" Research Policy, vol. 37, no. 3, pp. 473-491, 2008.

[34] E. Bacon, M. D. Williams, and G. H. Davies, "Recipes for success: conditions for knowledge transfer across open innovation ecosystems," International Journal of Information Management, vol. 49, no. 12, pp. 377-387, 2019.

[35] F.-S. Tsai, G. S. Baugh, S.-C. Fang, and J. L. Lin, "Contingent contingency: knowledge heterogeneity and new product development performance revisited," Asia Pacific Journal of Management, vol. 31, no. 1, pp. 149-169, 2014.

[36] S. Rodan, "Innovation and heterogeneous knowledge in managerial contact networks," Journal of Knowledge Management, vol. 6, no. 2, pp. 152-163, 2002.

[37] S. L. Brown and K. M. Eisenhardt, "Product Development: past research, present findings, and future directions," Academy of Management Review, vol. 20, no. 2, pp. 343-378, 1995.

[38] A. Toffler, The Third Wave, Bantam, NewYork, NY, USA, 1984.

[39] I. Nonaka, "A dynamic theory of organizational knowledge creation," Organization Science, vol. 5, no. 1, pp. 14-37, 1994.

[40] Z. Wang, J. Huang, H. Wang, J. Kang, and W. Cao, “Analysis of flood evacuation process in vulnerable community with mutual aid mechanism: an agent-based simulation framework," International Journal of Environmental Research and Public Health, vol. 17, no. 2, p. 560, 2020.

[41] C. M. Macal, "Everything you need to know about agentbased modelling and simulation," Journal of Simulation, vol. 10, no. 2, pp. 144-156, 2016.

[42] R. Garcia, "Uses of agent-based modeling in innovation/new product development research*," Journal of Product Innovation Management, vol. 22, no. 5, pp. 380-398, 2005.

[43] C. Stummer and E. Kiesling, "An agent-based market simulation for enriching innovation management education," Central European Journal of Operations Research, vol. 29, no. 1, pp. 143-161, 2020.

[44] C. P. Sankar, D. A. Thumba, T. R. Ramamohan, S. S. V. Chandra, and K. Satheesh Kumar, "Agent-based multi-edge network simulation model for knowledge diffusion through board interlocks," Expert Systems with Applications, vol. 141, Article ID 112962, 2020.

[45] C. Ryu, Y. J. Kim, A. Chaudhury, and fnm Rao, "Knowledge acquisition via three learning processes in enterprise information portals: learning-by-Investment, Learning-by-Doing, and Learning-from-Others," MIS Quarterly, vol. 29, no. 2, pp. 245-278, 2005. 
[46] C. Zheng, "Evolutionary game analysis of knowledge sharing in low-carbon innovation network," Complexity, vol. 2021, Article ID 9995344, 11 pages, 2021.

[47] L. E. Valdez-Juárez and M. Castillo-Vergara, “Technological capabilities, open innovation, and eco-innovation: dynamic capabilities to increase corporate performance of SMEs," Journal of Open Innovation: Technology, Market, and Complexity, vol. 7, no. 1, p. 8, 2021.

[48] H. Wang, J. Chen, and R. Zou, "Study on the coordinating mechanism of knowledge transfer of IURU collaborative innovation under modularity scenario," Studies in Science of Science, vol. 36, no. 07, pp. 1274-1283, 2018.

[49] K. Chen, J. Guan, M. Kou et al., "An applied study of network DEA model to the efficiency measurement of scientific and technologic innovation investment," Management Review, vol. 25, no. 12, pp. 3-14, 2013.

[50] A. Leckel, S. Veilleux, and L. P. Dana, "Local open innovation: a means for public policy to increase collaboration for innovation in SMEs," Technological Forecasting and Social Change, vol. 153, Article ID 119891, 2020.

[51] K. J. Xiong. "Economic policy uncertainty, enterprise heterogeneity and technological innovation--an empirical research from manufacturing enterprises in China," (accessed on: 16/03/2021), Available online:https://kns.cnki.net/kns/ brief/result.aspx?dbprefix $=$ CJFQ

[52] B. Hou, J. Hong, Q. Chen et al., "Do academia-industry R\&D collaborations necessarily facilitate industrial innovation in China? - - the role of technology transfer institutions," European Journal of Innovation Management, vol. 22, no. 5, pp. 717-746, 2019, https://www.emerald.com/insight/content/ doi/10.1108/EJIM-09-2018-0195/full/html.

[53] N. G. Novikova, N. T. Pirozhenko, L. N. Saburova, and E. V. Bokareva, "The role of financial institutions in the development of innovation in Russia," REICE: Revista Electrónica de Investigación en Ciencias Económicas, vol. 8, no. 16, pp. 361-371, 2020.

[54] M. B. Dahesh, G. Tabarsa, M. Zandieh, and M. Hamidizadeh, "Reviewing the intellectual structure and evolution of the innovation systems approach: a social network analysis," Technology in Society, vol. 63, Article ID 101399, 2020.

[55] Y. Su, X. S. Jiang, and Z. Z. Lin, "Simulation and relationship strength: characteristics of knowledge flows among subjects in a regional innovation system," Science, Technology and Society, https://journals.sagepub.com/doi/10.1177/09717218211 020476.

[56] L. Zhang and W. Chen, "How do innovation network structures affect knowledge sharing? A simulation analysis of complex networks," Complexity, vol. 2021, Article ID 5107630, 17 pages, 2021.

[57] C. Baldwin, C. Hienerth, and E. von Hippel, "How user innovations become commercial products: a theoretical investigation and case study," Research Policy, vol. 35, no. 9, pp. 1291-1313, 2006.

[58] E. Von Hippel, "Democratizing innovation: the evolving phenomenon of user innovation," Journal Fur Betriebswirtschaft, vol. 55, no. 1, pp. 63-78, 2005. 